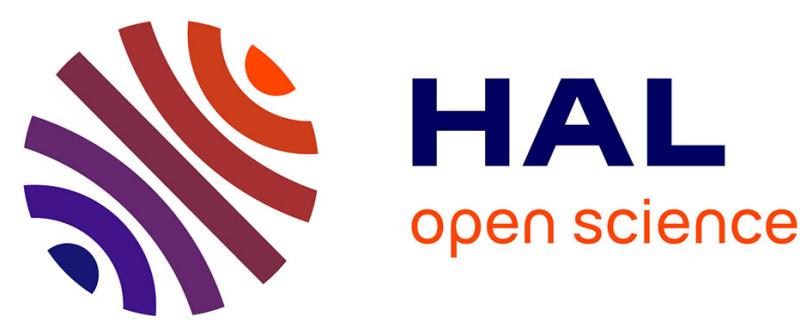

\title{
BIDIRECTIONAL REFLECTANCE OF OCEANIC WATERS - A COMPARISON OF MODELED AND MEASURED UPWARD RADIANCE FIELDS
}

\author{
A Morel, Kj Voss, B Gentili
}

\section{- To cite this version:}

A Morel, Kj Voss, B Gentili. BIDIRECTIONAL REFLECTANCE OF OCEANIC WATERS - A COMPARISON OF MODELED AND MEASURED UPWARD RADIANCE FIELDS. Journal of Geophysical Research. Oceans, 1995, 100 (C7), pp.13143-13150. 10.1029/95JC00531 . hal-03284968

\author{
HAL Id: hal-03284968 \\ https://hal.science/hal-03284968
}

Submitted on 13 Jul 2021

HAL is a multi-disciplinary open access archive for the deposit and dissemination of scientific research documents, whether they are published or not. The documents may come from teaching and research institutions in France or abroad, or from public or private research centers.
L'archive ouverte pluridisciplinaire HAL, est destinée au dépôt et à la diffusion de documents scientifiques de niveau recherche, publiés ou non, émanant des établissements d'enseignement et de recherche français ou étrangers, des laboratoires publics ou privés. 


\title{
Bidirectional reflectance of oceanic waters: A comparison of modeled and measured upward radiance fields
}

\author{
André Morel \\ Laboratoire de Physique et Chimie Marines, Universite Pierre et Marie Curie et CNRS \\ Villefranche-sur-Mer, France \\ Kenneth J. Voss \\ Physics Department, University of Miami, Coral Gables, Florida

\section{Bernard Gentili} \\ Laboratoire de Physique et Chimie Marines, Université Pierre et Marie Curie et CNRS \\ Villefranche-sur-Mer, France
}

\begin{abstract}
The bidirectional reflectance of oceanic waters is conveniently described in a normalized way by forming the ratio of the upwelling irradiance $E_{u}$ to any upwelling radiance $L_{u}\left(\theta^{\prime}, \varphi\right)$. This ratio, $Q\left[\theta^{\prime}, \theta_{0},\left(\varphi_{0}-\varphi\right)\right]$, where $\theta^{\prime}, \varphi$ are the nadir and azimuth angles for the upward radiance and $\theta_{0}, \varphi_{0}$ are the zenith and azimuth angles of the Sun, has been determined from measurements at sea and computed via Monte Carlo simulations using the inherent optical properties measured in the field and appropriate boundary conditions (clear sky, no wind, varying Sun angle). Experimental and computed $Q$ values are in excellent agreement. This successful comparison confirms the importance of the bidirectional character of ocean reflectance, already pointed out from a purely numerical approach without field validation, and corroborates the extended range of the $Q$ variations. The later point is of importance when interpreting the marine signals detected by an ocean color satellite-borne sensor. The validation is extended by considering the historical data for the radiance distributions in Lake Pend Oreille determined at various depths. The closure issue in ocean optics is examined by solving the direct problem of radiative transfer and through a model-data comparison in terms of radiance field.
\end{abstract}

\section{Introduction}

The upwelling radiances below the ocean surface do not form an isotropic radiance field, and this nonisotropic character has been previously studied through the use of an azimuthally dependent Monte Carlo code [Morel and Gentili, 1993]. The bidirectional reflectance function is conveniently described by the so-called " $Q$ factor" (in steradians), which relates any upwelling radiance $L_{u}\left(\theta^{\prime}, \varphi\right)$ to the upwelling irradiance $E_{u}$ at the same depth, according to (see also notation section).

$$
L_{u}\left(\theta_{0}, \theta^{\prime}, \Delta \varphi\right)=E_{u}\left(\theta_{0}\right) / Q\left(\theta_{0}, \theta^{\prime}, \Delta \varphi\right)
$$

with

$$
E_{u}\left(\theta_{0}\right)=\int_{\Xi_{u}} L_{u}\left(\theta_{0}, \theta^{\prime}, \Delta \varphi\right) \cos \theta^{\prime} d \Omega
$$

where $\theta_{0}$ is the zenith solar angle, $\theta^{\prime}$ is the nadir angle corresponding to the direction from which the radiance originates, and $\Delta \varphi$ represents the azimuth difference $(\Delta \varphi=\varphi$ $-\varphi_{0}$ ) between the vertical half planes containing the Sun and the radiance considered; the integration is performed

Copyright 1995 by the American Geophysical Union.

Paper number 95JC00531. 0148-0227/95/95JC-00531\$05.00 over the lower hemisphere ( $\Xi_{u}$, upward directions), and $\Omega$ is the solid angle. For what follows, $L_{u}$ and $E_{u}$ are computed or measured at the same depth $(1.5 \mathrm{~m})$ and the depth dependence of the above quantities is not explicitly noted.

It was also demonstrated [Morel and Gentili, 1993] that the spatial structure of the $Q$ function is dependent on the optical properties of the medium, namely, on the single scattering albedo $\bar{\omega}$ and on the ratio of the molecular scattering to total scattering $\eta$ defined as

$$
\begin{array}{cc}
\bar{\omega}=b / c & c=a+b \\
\eta=b_{w} / b & b=b_{w}+b_{p}
\end{array}
$$

where $a, b$, and $c$ are the absorption, scattering, and the beam attenuation coefficients, respectively; the (total) scattering coefficient is the sum of the molecular scattering $b_{w}$ and the particle scattering $b_{p}$. The $Q$ patterns for oceanic waters with several chlorophyll concentrations, wavelengths, Sun angles, and atmospheric conditions have been computed. It appears that $Q$ may vary between approximately 3 and 5 for solar and viewing angles typical of those involved in satellite-based ocean color observation (namely, $\theta^{\prime}$ restricted to be $<35^{\circ}$ in order to produce an emerging radiance inside the swath of a sensor, set at $\pm 50^{\circ}$, for instance). When considering all the upward directions $(0<$ $\theta^{\prime}<90^{\circ}$ ) including those corresponding to total reflection, the variations in $Q$ span over a more extended range, from 
below 1 up to 7 . In summary, using $\pi$ for $Q$ (as it will be for a Lambertian reflector) or ignoring the angular variations of the ocean reflectance is not justified, particularly in remote sensing applications. All the results summarized above are the products of theoretical considerations and numerical experiments. Even if forward Monte Carlo methods are able to mimic very closely all the phenomena determining the radiant field, a comparison with field data is definitely needed for a true validation.

The first detailed experimental evidence of anisotropy within the upwelling light field was provided by Jerlov and Fukuda [1960], Tyler [1960], and Sasaki et al. [1962]. Tyler, in 1957 and 1960, determined the down- and upwelling radiance distributions in Lake Pend Oreille (Idaho) at several depths. This complete data set (tabulated by Tyler and Preisendorfer [1962]) was thereafter regularly used for testing radiative transfer models [e.g., Preisendorfer, 1965; Prieur, 1976; Mobley, 1989]. Smith et al. [1970] designed a photographic system with two cameras placed back to back, each equipped with a $180^{\circ}$ field of view "fish-eye" lens. In the results of Tyler [1960] (at $\lambda=480 \mathrm{~nm}$ and at a depth of $4.24 \mathrm{~m}$ ), as well as in those of Smith [1974, Figure 8] (for $\lambda=$ $467 \mathrm{~nm}$ and $z=5 \mathrm{~m}$, Gulf of California), a factor of about 5 appears between the radiance in the horizontal direction (facing the Sun) and the nadir radiance, demonstrating the nonisotropic character of the $L_{u}$ field. As a consequence of this anisotropy, the $Q$ value pertinent to the nadir direction is greater than $\pi$, as discussed by Austin [1980].

The radiance distribution camera system ("RADS"), developed by Voss [1989], is based on two electro-optic cameras with two fish-eye lenses and allows the complete (down- and upwelling) radiance distribution to be simultaneously captured at various depths and wavelengths. A remotely operated spectral filter wheel in the optical path of each camera allows the radiance distribution to be obtained at four wavelengths, determined by interference filters. This equipment was operated during the Ocean Optics Closure cruise on the R/V New Horizon in August 1991, west of San Diego; 18 upwelling radiance field measurements were carried out on the August 26 at a station located at $32^{\circ} 40^{\prime} \mathrm{N}$ and $121^{\circ} 18^{\prime} \mathrm{W}$. The zenith Sun angle was varying from $32.2^{\circ}$ to $80.0^{\circ}$, while the sky conditions were perfectly clear.

A detailed comparison is possible therefore between this rather complete data set and Monte Carlo simulations. In addition, the radiant field determined near the surface (depth $Z=4.24$ and $10.4 \mathrm{~m}$ ) in Lake Pend Oreille provides another possibility of testing the $Q$ values predicted by the model in quite different conditions with regard to the optical properties of the water body. The first aim of such a comparison is to validate the previous theoretical findings and, in particular, to confirm the amplitude of the variations in $Q\left(\theta_{0}, \theta^{\prime}\right.$, $\Delta \varphi$ ). The second aim is to examine issues of closure in ocean optics via the solution of a "direct" problem of radiative transfer. It consists of using as inputs in the radiative transfer model the inherent optical properties (absorption and scattering), which were obtained from direct measurements in the field. With the appropriate boundary conditions the model produces apparent properties, and, in particular, the radiance distribution, to be compared to the independent measurements made with the RADS instrument or Tyler's [1960] radiance meter.

\section{Materials and Methods}

\section{Field Experiments}

The RADS instrument was calibrated using procedures described previously [Voss and Zibordi, 1989]. The instrument was deployed from an A-frame on the ship, approximately $2 \mathrm{~m}$ off the stern. The instrument depth was maintained at $1.0 \mathrm{~m}$, which meant that the upwelling sensor was at $1.5 \mathrm{~m}$. To minimize the ship shadow effect in the image [Helliwell et al., 1990], the ship was positioned to be approximately $90^{\circ}$ to the Sun's azimuth. In this manner one hemisphere of the radiance distribution was not contaminated, at least by first-order shadowing effects. The sea was almost flat calm, with a mirror flat surface disturbed by a small ( $<1-\mathrm{m}$ crest to trough), long-period sea swell. The ship maintained the $90^{\circ}$ orientation for most of the measurement period. Because of the shallow depth, no downwelling images are available. At this depth the dynamic range of the downwelling radiance distribution is larger than the system can measure, and flare due to the direct solar beam is unreasonably large.

The first step in the RADS data reduction is to apply the rolloff calibration. Since $Q$ is independent of the absolute calibration of the image, no absolute calibration factor was applied. The camera image extends to $80^{\circ}$ from the nadir. This image was extrapolated to the horizon by using a fitting routine and the data between $70^{\circ}$ and $80^{\circ}$. In these images the radiance appeared to increase in a logarithmic fashion toward the horizon. The angles between 70 and $80^{\circ}$ were chosen, as they represent reliable data and are close to the extrapolation region. For each $5^{\circ}$ azimuthal increment the fitting routine used a least squares linear fit to the log of the radiance and nadir angle. The line determined by the fit was used in the extrapolation. The image was split in two along the line containing the nadir and the antisolar direction. The half of the image containing the direct ship shadow was discarded. For the most part this removed the obvious ship shadow, however, in several images small ship shadow effects are still evident. Unfortunately, after all the measurements had been obtained, it was discovered that two small screws were loose and lying in the window dome of the camera; these screws were in focus and can easily be identified in the images. They show up as small area perturbations in the images. These are removed in the data discussed below. Instrument self-shadow effects [MacDonald et al., 1991] may still perturb the radiance obtained but cannot be reasonably avoided. The irradiances determined by the images should not be significantly affected, however, this instrumental perturbation effect will be largest in the longer wavelengths because of the increasing absorption [Gordon and Ding, 1992]. Measurements (summarized in Table 1) were obtained at the following three wavelengths: 450,500 , and $600 \mathrm{~nm}$ (with $\Delta \lambda=25 \mathrm{~nm}$ ).

\section{Numerical Experiments}

The Monte Carlo code has already been described in detail [Morel and Gentili, 1991, 1993] and checked against other codes and methods to solve a set of canonical problems of radiative transfer [Mobley et al., 1993]. For the present comparison with the radiance data, the inherent optical properties pertinent to the water bodies considered have been used as input in the radiative transfer model.

Just before and after the RADS measurements, the verti- 
cal profile of the beam attenuation coefficient was determined at $491 \mathrm{~nm}$. Near the surface the difference $c(491)-$ $c_{w}(491)$ was $0.256 \mathrm{~m}^{-1}\left(c_{w}\right.$ represents the attenuation coefficient for pure water, taken in the work by Smith and Baker [1981]). In addition, other vertical profiles of $c$ were determined during the same cruise (and at this location) using five wavelengths $(440,491,520,550$, and $670 \mathrm{~nm})$. These measurements have demonstrated that the differences $c(\lambda)-c_{w}(\lambda)$ are all linearly related $\left(r^{2}>0.987\right)$ to the difference $c(491)-c_{w}(491)$ with known slopes, which confirm those already derived from historical measurements [Voss, 1992]. With these slopes (Table 2) it is easy to arrive at $c$ values for the appropriate wavelengths $(450,500$, and $600 \mathrm{~nm})$. For the experiment in Lake Pend Oreille the $c$ and $b$ values were provided and are also reproduced in Table 2 .

During the Ocean Optics Closure cruise, at the same location and depth of RADS measurements, particulate absorption spectra were measured by G. Mitchell (Scripps Institution of Oceanography) and provided to us. They have been measured on glass filter (GF/F Whatman) by using a Perkin-Elmer Lambda-6 spectrophotometer and corrected for the path length amplification according to the equation given by Mitchell [1990] to provide the spectral $a_{p}(\lambda)$ values. They are added to the absorption contribution of pure water $a_{w}(\lambda)$ [Smith and Baker, 1981] to obtain the absorption coefficients displayed in Table 2 . Then, the scattering coefficient is computed as $b(\lambda)=c(\lambda)-a(\lambda)$ and the ratio $\eta$ is derived. In the Monte Carlo simulation the $\eta$ ratio determines the probability for a photon to be scattered either by molecules or by particles. The corresponding scattering phase functions $\bar{\beta}(\psi)$ are as given by Morel and Gentili [1991], namely, for pure seawater

$$
\bar{\beta}_{w}(\psi)=\frac{3}{4 \pi(3+p)}\left(1+p \cos ^{2} \psi\right)
$$

( $\psi$ is the scattering angle, and $p$ is the polarization factor $=$ 0.84), and for particles the Petzold [1972] function is adopted (as tabulated by Mobley et al. [1993]). According to Morel [1991, equations (19) and (20)], with the $a$ and $b$ values shown in Table 2, the water off San Diego belongs to case 1 waters, with a chlorophyll concentration of about $0.3 \mathrm{mg}$ $\mathrm{m}^{-3}$ as actually observed near the surface (mean value: 0.24

Table 1. Zenith Sun Angles at the Instant of the Upwelling Radiance Determinations

\begin{tabular}{|c|c|c|c|}
\hline \multicolumn{3}{|c|}{ West of San Diego } & \multirow{2}{*}{$\begin{array}{c}\text { Lake Pend } \\
\text { Oreille, } \\
480 \mathrm{~nm}\end{array}$} \\
\hline $450 \mathrm{~nm}$ & $500 \mathrm{~nm}$ & $600 \mathrm{~nm}$ & \\
\hline 32.2 & 50.7 & $50.6^{*}$ & $\cdots$ \\
\hline $58.2 \dagger$ & $59.7 \dagger$ & $58.8^{*}+\dagger$ & $\cdots$ \\
\hline $63.4^{*} \dagger$ & $65.5^{*}+\dagger$ & $64.7^{*, \dagger}$ & 33.4 \\
\hline $69.8 \dagger$ & $71.4^{*, \dagger}$ & $70.1^{*, \dagger}$ & $\cdots$ \\
\hline $73.3 \dagger$ & $74.5 \dagger$ & $77.3^{*}+\dagger$ & $\cdots$ \\
\hline $76.4 \dagger$ & $77.7 \dagger$ & $\cdots$ & $\cdots$ \\
\hline $80.0 \dagger$ & $\cdots$ & $\cdots$ & $\cdots$ \\
\hline
\end{tabular}

All values are in degrees.

*Images with darkened zones in the antisolar directions (in Plate 1 they correspond to anomalously high $Q$ values in the $150-180^{\circ}$ azimuth sector, and at $600 \mathrm{~nm}$, to the red spot centered at $\theta^{\prime} \sim 60^{\circ}$, $\Delta \varphi=180^{\circ}$ ).

$\dagger$ Images with artifacts near the nadir direction (in Plate 1 they are seen as thin aigrettes originating from the center).
Table 2. Relevant Inherent Optical Properties of the Oceanic Water Where the Radiance Distribution Camera System Measurements Were Carried Out and of the Lake Pend Oreille Water

\begin{tabular}{|c|c|c|c|c|}
\hline \multirow[b]{2}{*}{ Wavelength, nm } & \multicolumn{3}{|c|}{ RADS } & \multirow[b]{2}{*}{$480 \mathrm{~nm}^{*}$} \\
\hline & $450 \mathrm{~nm}$ & $500 \mathrm{~nm}$ & $600 \mathrm{~nm}$ & \\
\hline Slope & 1.045 & 0.988 & 0.874 & $\cdots$ \\
\hline$c-c_{w}, \mathbf{m}^{-1}$ & 0.267 & 0.254 & 0.224 & $\cdots$ \\
\hline$c_{w}, \mathbf{m}^{-1}$ & 0.019 & 0.0286 & 0.246 & $\cdots$ \\
\hline$c, \mathrm{~m}^{-}$ & 0.286 & 0.283 & 0.470 & 0.402 \\
\hline$a_{p}, \mathrm{~m}^{-1}$ & 0.026 & 0.016 & 0.006 & $\cdots$ \\
\hline$a_{w}, \mathrm{~m}^{-1}$ & 0.0145 & 0.0257 & 0.244 & $\cdots$ \\
\hline$a, \mathrm{~m}^{-1}$ & 0.0400 & 0.0420 & 0.250 & 0.117 \\
\hline$b=c-a, \mathrm{~m}^{-1}$ & 0.246 & 0.241 & 0.220 & 0.285 \\
\hline$b_{w}, \mathrm{~m}^{-1}$ & 0.0045 & 0.0029 & 0.0014 & 0.0026 \\
\hline$b / c=\bar{\omega}$ & 0.860 & 0.851 & 0.468 & 0.709 \\
\hline$\eta=b_{w} / b$ & 0.0183 & 0.0121 & 0.0064 & 0.0091 \\
\hline
\end{tabular}

These coefficients are used as inputs in the Monte Carlo simulations, with the solar angles in Table 1.

* Lake Pend Oreille water [Tyler, 1960].

$\mathrm{mg} \mathrm{m}^{-3}$ at 0 and $15 \mathrm{~m}$, just before and after the RADS measurements). Case 1 waters are those where the optical properties are chiefly determined by algal cells and their associate materials and are not significantly influenced by terrigeneous, dissolved, or suspended materials [see Gordon and Morel, 1983]. The scattering coefficient $\left(0.23 \mathrm{~m}^{-1}\right.$ at 550 $\mathrm{nm}$, as interpolated in Table 2) appears to be close to the upper bound for case 1 waters, namely,

$$
b_{p}(550) \simeq 0.45(\mathrm{Chl})^{062}
$$

where the mean value of the coefficient $(0.30)$ shown by Gordon and Morel [1983] is replaced by its upper limit value, 0.45. As pointed out by Gordon and Morel, near-surface waters are, in most cases, close to the upper limit. Compared with the oceanic waters, the freshwater body of Lake Pend Oreille is about 3 times more absorbing, with similar scattering properties.

The boundary conditions for the simulation are fixed according to the observations. During the RADS measurements the sky was cloudless, and according to the ship's log, the weather was "spectacularly good." The model was operated in its coupled version (atmosphere and ocean). For the atmospheric segment, 50 1-km-thick layers were considered with specified values for Rayleigh and aerosol scattering and for ozone and water vapor absorption as by Elterman [1968]. The aerosol content was adjusted to provide a visibility of $23 \mathrm{~km}$. The air-water interface was modeled using the isotropic Gaussian distribution of sea surface slopes, with a wind speed set at zero, leaving a weak residual agitation in correspondence with the constant term in the Cox and Munk [1955] expression. The zenith sun angle $\theta_{0}$ is known at the moment of each radiance field measurement, and these $\theta_{0}$ values were thus used for each of the simulations. In addition, three other values $\left(\theta_{0}=0,20\right.$, and $\left.40^{\circ}\right)$ were also considered in order to explore the full range of $Q$ value, beyond that of the values measured during the field experiment. The same boundary conditions (no wind, clear sky) were adopted for the simulation of the Lake Pend Oreille experiment. The molecular scattering $b_{w}$ for optically pure fresh water [Morel, 1974] was used instead of that 
for pure seawater. The Sun's angular diameter is set at half a degree.

To construct the upward radiance field at each selected depth, the upward traveling photons are collected into 480 detectors corresponding to equal solid angles $\left(6.5410^{-3} \mathrm{sr}\right)$ with 20 polar directions $\left(0.05\right.$ increments in $\cos \theta^{\prime}$, from 0 to 1 , i.e., from horizon to nadir) and 24 azimuthal directions $\left(7.5^{\circ}\right.$ increments in $\Delta \varphi$, from 0 to $180^{\circ}$ ). Because of the symmetry with respect to the solar plane, the sign of $\Delta \varphi$ is neglected. The appropriate integration of the $L_{u}$ field provides $E_{u}$, and $Q\left(\theta_{0}, \theta^{\prime}, \Delta \varphi\right)$ is computed according to (1). The entire (upward and downward) radiance field actually is available in the simulation, as $\mathbf{4 8 0}$ other detectors, arranged in the same way but oriented toward the upper hemisphere, collect the downward oriented photons.

\section{Results and Discussion \\ Upward Radiance Field and $\boldsymbol{Q}$ Values}

For the same reason of symmetry, only half of the field of view of the RADS camera is kept for comparison with the computed results. This allows the ship shadow to be eliminated in most of the cases; some vestiges of this shadow, however, contaminate a few images. The pixels within the image are resampled and averaged to coincide with the contiguous, regularly spaced, solid angles adopted in the simulation. Knowing $E_{u}$ from the appropriate integration over the entire field of view, the resampled $L_{u}$ can be transformed into $Q$ values, so that the comparison with the Monte Carlo data, transformed in the same way, is straightforward. Some selected examples of the actual and simulated data (one per wavelength) are shown in Plate 1. The whole set of comparative data will be displayed later on.

As mentioned previously, the screws leave a small artifact near the nadir direction and for all wavelengths. There is also an anomalously dark zone (high $Q$ values) in the antisolar plane ( $\Delta \varphi$ approaching $\pi$ ) and in directions corresponding to $\theta^{\prime}=50-70^{\circ}$. This anomaly is distinctly seen in the $600-\mathrm{nm}$ pictures, yet also weakly detectable at 500 and $450 \mathrm{~nm}$. This is probably some vestige of an instrument self-shadowing effect, however, it is not exactly in the antisolar direction. Disregarding these "contaminated" zones, the agreement between predicted and measured $Q$ fields is excellent in terms of pattern and values.

As expected [Morel and Gentili, 1993], the maximal $Q$ values are steadily found in the vicinity of nadir, and the minimal ones occur in the horizontal directions $\left(\theta^{\prime}=\pi / 2\right)$ and always in the solar half plane $(\Delta \varphi=0)$. These features, as well as the overall (solar/antisolar) dissymmetry, are very similar in the actual and simulated $Q$ fields. With regard to the magnitude of the $Q$ values the numerical comparison first requires that the contaminated pixels within the RADS data set be eliminated. Those near the nadir, with a high artifactual contrast, are easily isolated and canceled out. The anomalously darkened portions of the field of view in the antisun direction are excluded by disregarding the azimuthal directions from 150 to $180^{\circ}$ (whatever the $\theta^{\prime}$ value). As a consequence of this sorting, about 360 (up to 400 ) $Q$ values are kept over the 480 values normally available in each RADS image. They are plotted as a function of the corresponding computed values (Figure 1); for each wavelength all the data are pooled together, regardless of the Sun angle.

Considering that experimental or stochastic noises inevi-

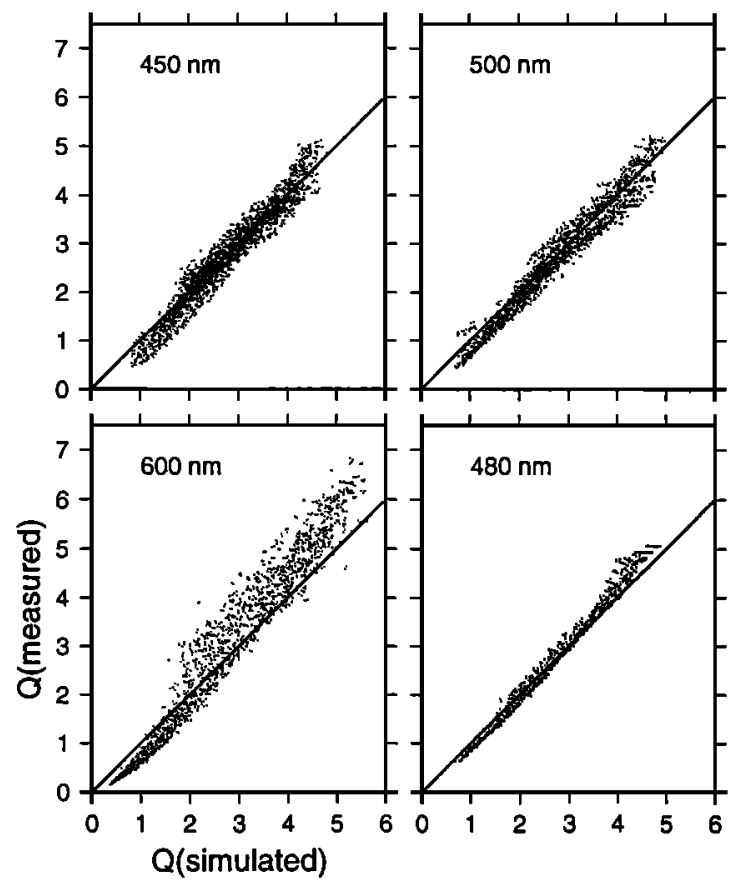

Figure 1. Experimental $Q$ values versus computed $Q$ values. The contaminated pixels in the radiance distribution camera system (RADS) data have been eliminated (see text). For each wavelength $(450,500$, and $600 \mathrm{~nm})$ the results for various Sun angles are pooled together. For $\lambda=480 \mathrm{~nm}$ (Lake Pend Oreille) the $Q$ values for two depths (4.24 and $10.4 \mathrm{~m}$ ) are merged. Note that only $Q$ values from about 3-7 are in positions relevant for above surface observations.

tably exist in the experimental or simulated data, the agreement between the two sets is remarkable over the full range (from $<1$ and up to 5) without any bias for the wavelengths 450,480 , and $500 \mathrm{~nm}$. At $600 \mathrm{~nm}$ a conspicuous deviation appears between the actual and simulated values. Some of the differences at $600 \mathrm{~nm}$ may be explained by the increased noise in the measurements at these wavelengths. Owing to the low water reflectance at this wavelength, increased integration times are required, which increases the dark noise fluctuations. This is also the wavelength for which shadowing, both by ship and instrument, has a larger impact. Even if the general trends at $600 \mathrm{~nm}$ are similar in the two kinds of data, the minimal $Q_{\min }$ and maximal $Q_{\max } Q$ values span over a range, more extended in the experimental data set than in the simulations. According to previous results, the overall dissymmetry, i.e., the difference between $Q_{\min }$ and $Q_{\max }$ is mainly governed by the $\eta$ value, at least for the present $\bar{\omega}$ values [Morel and Gentili, 1993, Figure 4]. This difference increases for diminishing $\eta$ values. At $600 \mathrm{~nm}, \eta$ is already very low (0.0064), and even if the experimental $b$ value used as input could be somewhat inaccurate, its underestimate cannot be large enough to substantially modify $\eta$ and thus the $Q_{\min }-Q_{\max }$ interval. With a low $\bar{\omega}$ value and, consequently, the reduced mean number of scattering events (1.88, according to Morel and Gentili [1991, equation (19)]) the shape of the phase function may intuitively be influential on the structure of the radiant field. The composite (detritus and phytoplankton) phase function (Gordon [1992, equation (15)] used with a chlorophyll concentration of $0.35 \mathrm{mg} \mathrm{m}^{-3}$ ), characterized by an increased forward 


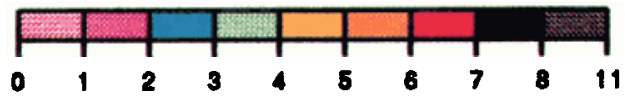

\section{Q-factor}
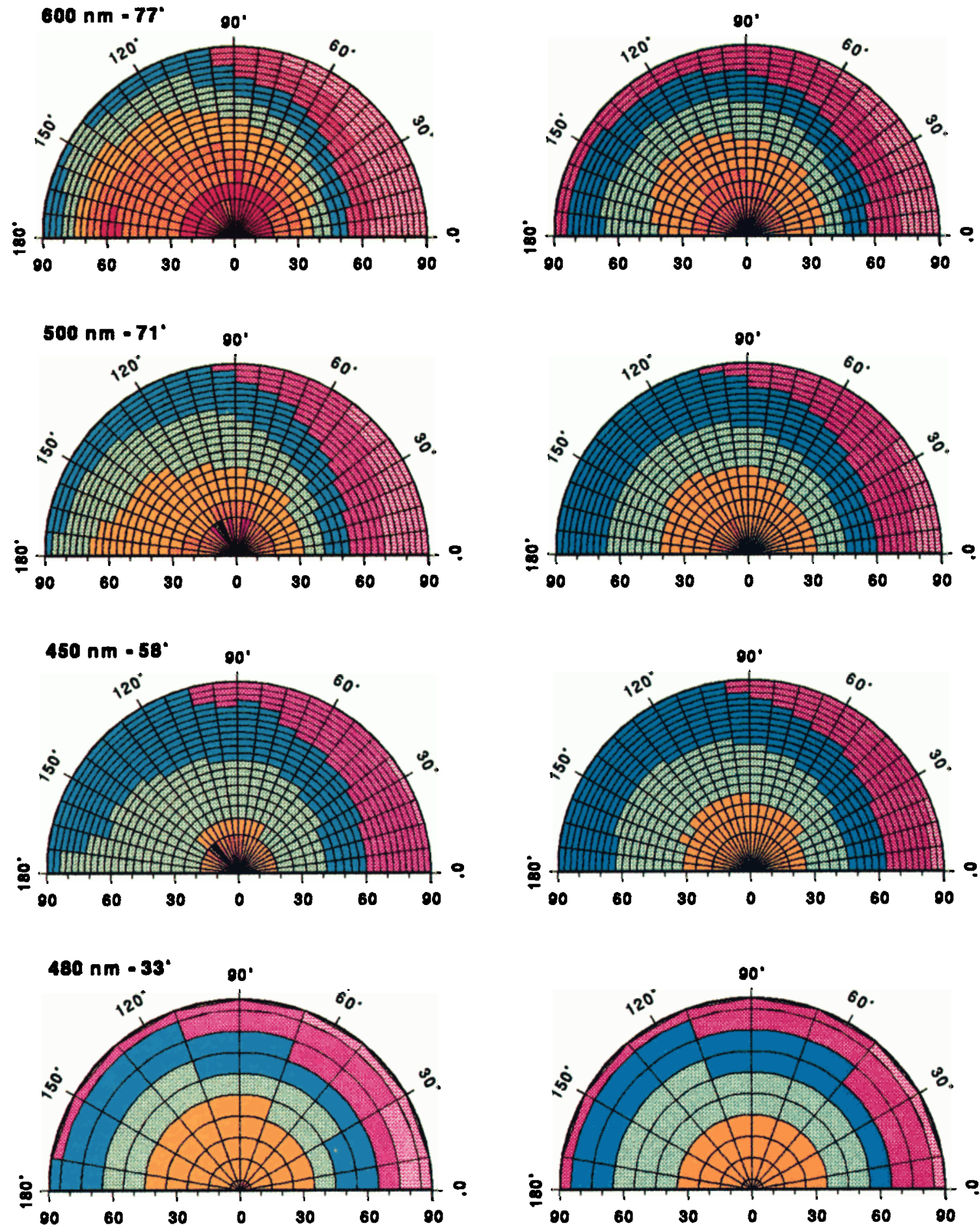

Plate 1. Polar plots of the $Q$ factor as derived from (left) measurements and (right) computations. The center of each plot represents the nadir direction, and the outer half circle is the horizontal direction; the nadir angles $\theta^{\prime}$ are linearly distributed along the radius. The azimuth difference $\Delta \varphi$ varies from 0 to $180^{\circ}$ and is $\mathbf{0}$ for the vertical half plane containing the Sun. The $Q$ values are all plotted with no attempt to eliminate experimental or computational noise. The field data for Lake Pend Oreille (bottom) are plotted according to the discrete values as tabulated by Tyler and Preisendorfer [1962]. Relevant information (wavelength and zenith Sun angle) and color encoding are provided. 


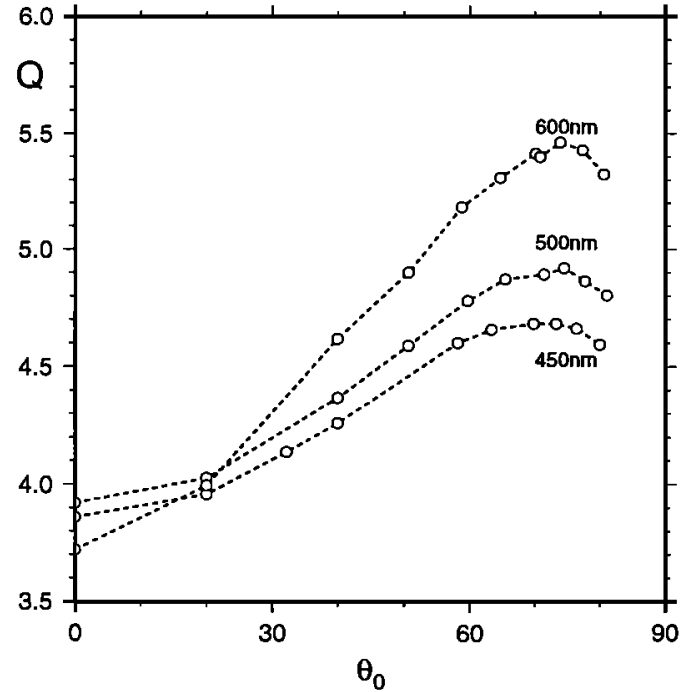

Figure 2. $Q$ values for the nadir radiance computed for the oceanic water where the RADS instrument was operated and for varying solar zenith angle $\theta_{0}\left(0\right.$ to $\left.80^{\circ}\right)$.

narrow peak and, correlatively, a lower backscattering probability, has been used to test this hypothesis. The simulations with this modified phase function do not entail any palpable and significant change in the relative upwelling radiance distribution and therefore in the $Q$ field. However, and for lack of reliable information, the shape of the volume scattering function in the backward direction was not changed, although this shape is very important in this situation where single scattering prevails.

For the same oceanic water the Monte Carlo simulations have been made with smaller $\theta_{0}$ values to describe the full possible range of $Q$ values. In Figure 2, only the $Q$ values pertinent to upwelling radiance, supposedly measured with a radiometer aiming at nadir with a field of view of $18^{\circ}$ (half angle), are plotted. With the atmospheric conditions adopted for the simulations the $Q\left(\theta_{0}, 0\right)$ factor exhibits a maximum for $\theta_{0}=75^{\circ}$, the minimum being for $\theta_{0}=0$. The full range of variations in $Q\left(\theta_{0}, 0\right)$ is about 22,25 , and $48 \%$ for $\lambda=450$, 500 , and $600 \mathrm{~nm}$, respectively. The amplitude of these changes demonstrates the need for corrections, when in situ or in situ/space measurements made under various Sun illuminations have to be compared and analyzed. If the trends shown in Figure 2 are general (see also Morel and Gentili [1993 Figure 13]), the $Q$ values and their evolutions differ according to the water properties, so that the corrections have to be made specific.

\section{The Solution of the Direct Problem}

The results discussed above are oriented toward a practical application in the remote sensing problem. However, they also form a model-data comparison exercise and demonstrate that the direct problem can be accurately solved. In addition, the $K_{d}$ values ( $K_{d}$ is the diffuse attenuation coefficient for downwelling irradiance) computed via the model have been compared with those (at different wavelengths) measured in the Pacific waters on the same day (Figure 3); the agreement is quite satisfactory.

A more complete validation of the numerical solution, including all depths and involving the whole radiance field, is displayed in Figure 4. The data for Lake Pend Oreille in the solar plane and in the plane perpendicular to the Sun plane are superimposed on the predicted radiance distributions. For the perpendicular plane the data for $\Delta \varphi=80^{\circ}$ and $100^{\circ}$ have been averaged to produce the values at $\Delta \varphi=90^{\circ}$ for the sake of comparison. Without discussing the details in Figure 4 , the capacity of the model in solving the direct problem, including in the approach of the asymptotic diffuse regime, is clearly demonstrated.

\section{Conclusions}

In reference to the two aims of the present work it can be concluded that the importance of the bidirectional character of the ocean reflectance, which was previously emphasized on the sole basis of numerical experiments, combined with reasonable, yet debatable, assumptions [Morel and Gentili, 1993], is now fully confirmed by the goodness of fit between field and simulated data. This process, ignored when processing the coastal zone color scanner data, can no longer be neglected in algorithms to be developed for the next generation of radiometrically more accurate ocean color sensors.

Solving the direct radiative transfer problem in terms of radiance distribution is the more stringent way of validating a model. Radiance, i.e., the fundamental radiometric quantity, is also more sensitive than integrated quantities, such as irradiances, to any weakness in the computational scheme or in theoretical representation of the real world on which the scheme is based. The performances of the model used here have already been evaluated via a model-model comparison [Mobley et al., 1993]. The recent and detailed upwelling radiance fields determined for varying Sun angle and the historical Tyler's [1960] measurements with varying depths constitute an adequate data set for a comprehensive modeldata comparison. From the agreement between the numeri-

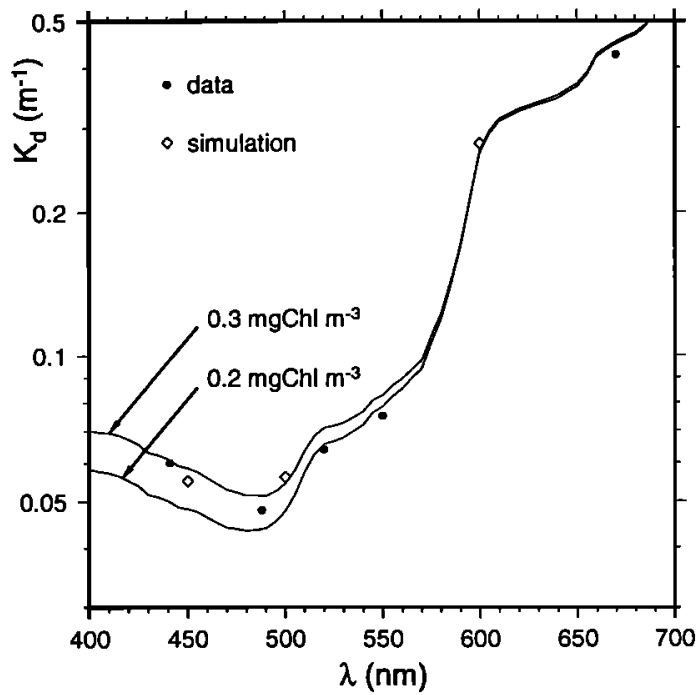

Figure 3. Measured (dots) and computed (diamonds) values of the diffuse attenuation coefficient for downwelling irradiance at the location of the RADS experiment. The two spectra, for oceanic water with a chlorophyll concentration of 0.2 and $0.3 \mathrm{mg} \mathrm{m}^{-3}$, are computed according to Morel's [1988] model; from the determinations at 0 and $15 \mathrm{~m}$, just before and after the RADS measurements, the averaged chlorophyll concentration amounted to $0.24 \mathrm{mg} \mathrm{m}^{-3}$. 


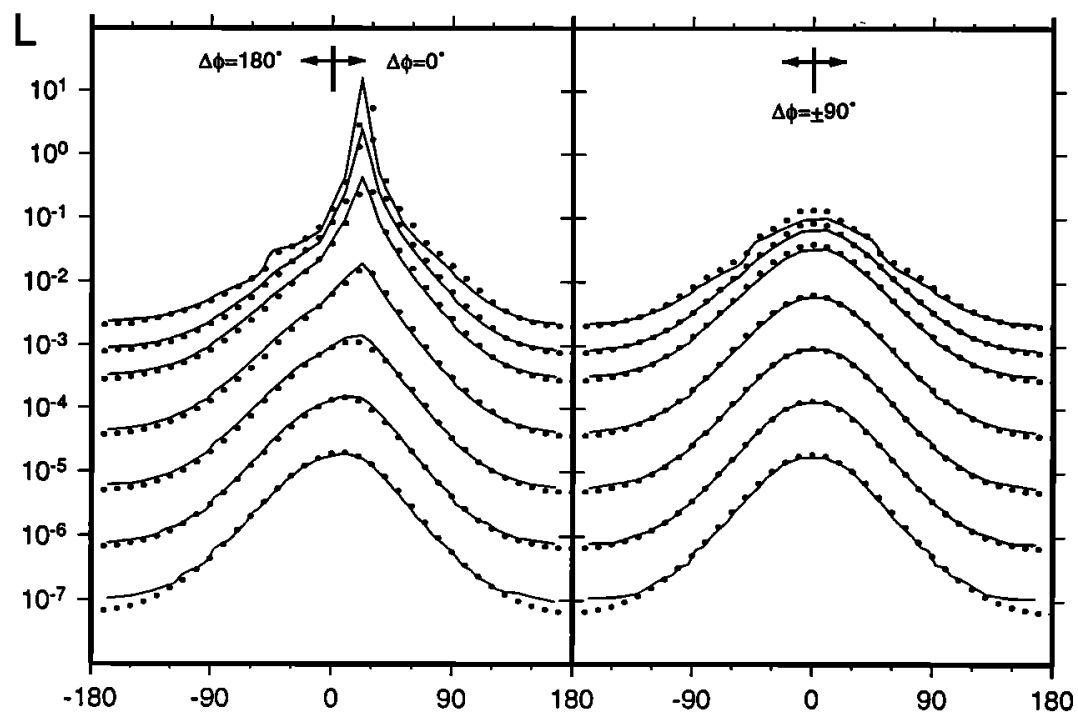

Figure 4. Computed (curves) and measured (dots) radiances as a function of the zenith angle in the (left) solar plane and in the (right) plane perpendicular to the Sun direction. From top to bottom the results shown are for the following depths: 4.24, 10.4, 16.6, 29.0, 41.3, 53.7, and 66.1 $\mathrm{m}$ in Lake Pend Oreille.

cal outputs and field data it can be concluded that the model is successfully validated.

\section{Notation}

$a$ total absorption coefficient $\left(a=a_{w}+a_{p}\right), \mathrm{m}^{-1}$.

$a_{w}$ pure water absorption coefficient, $\mathbf{m}^{-1}$.

$a_{p}$ particle absorption coefficient, $\mathrm{m}^{-1}$.

$b$ total scattering coefficient $\left(b=b_{w}+b_{p}\right), \mathrm{m}^{-1}$.

$b_{w}$ pure water scattering coefficient, $\mathrm{m}^{-1}$.

$b_{p}$ particle scattering coefficient, $\mathrm{m}^{-1}$.

$c$ attenuation coefficient $(c=a+b), \mathrm{m}^{-1}$.

$c_{w}$ attenuation coefficient for pure water, $\mathrm{m}^{-1}$.

$\overline{\boldsymbol{\beta}}_{w}$ pure water phase function (molecular scattering).

$\bar{\beta}_{p}$ particle phase function.

$\psi$ scattering angle.

$\bar{\omega}$ single scattering albedo $(\bar{\omega}=b / c)$.

$\eta$ ratio of molecular scattering to total scattering ( $\eta$ $\left.=b_{w} / b\right)$.

$\theta^{\prime}$ nadir angle of the direction from which the radiance originates.

$\varphi$ azimuth angle of the direction from which the radiance originates.

$\theta_{0} \quad$ zenith solar angle.

$\Delta \varphi$ azimuth difference between the vertical half planes containing the Sun and the radiance considered.

$E_{u}$ upwelling irradiance, $\mathrm{W} \mathrm{m}^{-2}$.

$L_{u} \quad$ upwelling radiance, $\mathrm{W} \mathrm{m} \mathrm{m}^{-2} \mathrm{sr}^{-1}$.

$Q \quad Q$ factor $\left(Q=E_{u} / L_{u}\right)$, sr.

(Chl) chlorophyll concentration, $\mathrm{mg} \mathrm{m}^{-3}$.

$\lambda$ wavelength, $\mathrm{nm}$.

Acknowledgments. We would like to thank Greg Mitchell for providing the particulate absorption measurements. The experimental work was supported by the Ocean Optics program at the Office of Naval Research, grant N00014-90-1505, and National Aeronautics and Space Administration, grant NAGW-273 and contract NAS531363. The theoretical work was funded by European Space Agency under contract OT/MM/612. The support of these agencies is duly acknowledged. This work is dedicated to the memory of John E. Tyler.

\section{References}

Austin, R. W., Coastal Zone Color Scanner radiometry, in Ocean Optics 6, Proc. SPIE Int. Soc. Opt. Eng., 208, 170-177, 1980.

Cox, C., and W. Munk, Some problems in optical oceanography, $J$. Mar. Res., 14, 63-78, 1955.

Elterman, L., UV, visible, and IR attenuation for altitudes to $50 \mathrm{~km}$, Rep. AFCRL-68-0153, U.S. Air Force Cambridge Res. Lab., Bedford, Mass., 1968.

Gordon, H., and A. Morel, Remote Assessment of Ocean Color for Interpretation of Satellite Visible Imagery: A Review, 114 pp., Springer-Verlag, New York, 1983.

Gordon, H. R., Diffuse reflectance of the ocean: Influence of non-uniform phytoplankton pigment profile, Appl. Opt., 31, 21162129, 1992.

Gordon, H. R., and K. Ding, Self-shading of in-water optical instruments, Limnol. Oceanogr., 37, 491-500, 1992.

Helliwell, W. S., G. N. Sullivan, B. MacDonald, and K. J. Voss, Ship shadowing: model and data comparisons, in Ocean Optics 10, Proc. SPIE Int. Soc. Opt. Eng., 1302, 55-71, 1990.

Jerlov, N. G., and M. Fukuda, Radiance distribution in the upper layers of the sea, Tellus, 12, 348-355, 1960.

MacDonald, B., W. S. Helliwell, J. Sanborn, and K. J. Voss, Detector perturbation of ocean radiance measurements, in Underwater imaging, photography, and visibility, Proc. SPIE Int. Soc. Opt. Eng., 1537, 104-114, 1991.

Mitchell, B. G., Algorithms for determining the absorption coefficient for aquatic particulates using the quantitative filter technique, in Ocean Optics 10, Proc. SPIE Int. Soc. Opt. Eng., 1302, 137-148, 1990.

Mobley, C. D., A numerical model for the computation of radiance distributions in natural waters with wind-roughened surfaces, Limnol. Oceanogr., 34, 1473-1483, 1989.

Mobley, C. D., B. Gentili, H. R. Gordon, J. Zhonghai, G. W. Kattawar, A. Morel, P. Reinersman, K. Stamnes, and R. H. Stavn, Comparison of numerical models for computing underwater light fields, Appl. Opt., 32, 7484-7504, 1993.

Morel, A., Optical properties of pure water and pure sea water, in Optical Aspects of Oceanography, edited by N. G. Jerlov and E. Steemann Nielsen, pp. 1-24, Academic, San Diego, Calif., 1974. Morel, A., Optical modeling of the upper ocean in relation to its biogenous matter content (case I waters), J. Geophys. Res., 93, $10,749-10,768,1988$. 
Morel, A., and B. Gentili, Diffuse reflectance of oceanic waters: Its dependence on sun angle as influenced by the molecular scattering contribution, Appl. Opt., 30, 4427-4438, 1991.

Morel, A., and B. Gentili, Diffuse reflectance of oceanic waters: Bidirectional aspects, Appl. Opt., 32, 6864-6879, 1993.

Petzold, T. J., Volume scattering functions for selected ocean waters, Rep. 510 Ref. 72-78, 79 pp., Scripps Inst. of Oceanogr., La Jolla, Calif., 1972.

Preisendorfer, R. W., Radiative Transfer on Discrete Space, 462 pp., Pergamon, Tarrytown, N. Y., 1965.

Prieur, L., Transfert radiatif dans les eaux de mer: Application à la détermination des paramètres optiques caractérisant leur teneur en substances dissoutes et particulaires, thèse d'etat, Univ. Pierre et Marie Curie, Paris, 1976.

Sasaki, T., S. Watanabe, G. Oshiba, N. Okami, and M. Kajihara, On the instrument for measuring angular distribution of underwater radiance, Bull. Jpn. Soc. Sci. Fish., 28, 489-496, 1962.

Smith, R. C., Structure of solar radiation in the upper layers of the sea, in Optical Aspects of Oceanography, edited by N. G. Jerlov and E. Steeman Nielsen, pp. 95-117, Academic, San Diego, Calif., 1974.

Smith, R. C., and K. S. Baker, optical properties of the clearest natural waters, Appl. Opt., 20, 177-184, 1981.

Smith, R. C., W. Austin, and J. E. Tyler, An oceanographic radiance distribution camera system, Appl. Opt., 9, 2015-2022, 1970.
Tyler, J. E., Radiance distribution as a function of depth in a underwater environment, Bull. Scripps Inst. Oceanogr., 7, 363412, 1960.

Tyler, J. E., and R. W. Preisendorfer, Transmission of energy within the sea, in The Sea, vol. 1, edited by M. N. Hill, pp. 397-448, Wiley-Interscience, New York, 1962.

Voss, K. J., Electro-optic camera system for measurement of the underwater radiance distribution, Opt. Eng., 28, 241-247, 1989.

Voss, K. J., A spectral model of the beam attenuation coefficient in the ocean and coastal areas, Limnol. Oceanogr., 37, 501-509, 1992.

Voss, K. J., and G. Zibordi, Radiometric and geometric calibration of a visible spectral electro-optic "fisheye" camera radiance distribution system, J. Atmos. Oceanic Technol., 6, 652-662, 1989.

B. Gentili and A. Morel, Laboratoire de Physique et Chimie Marines, Université Pierre et Marie Curie et CNRS, BP8, F06230 Villefranche-sur-Mer, France. (e-mail: morel@ccrv.obs-vlfr.fr)

K. J. Voss, Physics Department, University of Miami, Coral Gables, FL 33124

(Received April 11, 1994; revised August 3, 1994; accepted November 29, 1994.) 